\title{
REPORT
}

\section{Signalling in osteoclasts and the role of Fos/API proteins}

\author{
E F Wagner, K Matsuo
}

Ann Rheum Dis 2003;62(Suppl II):ii83-ii85

$\mathrm{T}$ he analysis of genetically modified mice and cells has provided important new insights into the biological functions of the dimeric transcription factor complex APl. The key components of APl, the Fos and Jun proteins, have essential roles in bone development, because these proteins influence the activity of all bone cells, including chondrocytes, osteoblasts, and osteoclasts. New APl functions and their downstream effectors were recently discovered using conditional mutagenesis in the mouse as well as by genome-wide analysis of AP1 inducible genes, in particular in the osteoclast lineage.

The signal transduction pathways operating in osteoclastogenesis have been extensively studied and how extracellular stimuli lead to the activation of key transcriptional programmes is beginning to be understood. The events downstream of macrophage colony-stimulating factor (M-CSF) and receptor activator of $\mathrm{NF}-\mathrm{\kappa B}$ ligand (RANKL) signalling are well described. Positive and negative regulatory loops are in place, which involve the activation of NF- $\mathrm{kB}$ and Jun $\mathrm{N}$-terminal kinase (JNK), eventually leading to the expression of $\mathrm{APl} / \mathrm{Fos}$, an essential regulator of osteoclast differentiation.

APl consists of a large variety of dimers composed of members of the Fos proteins-Fos, FosB, Fral, and Fra2; the three Jun proteins-Jun, JunB, and JunD; and ATF proteins (for review see Karsenty and Wagner ${ }^{1}$ and Jochum et $a l^{2}$ ). APl acts like a biosensor in cells and is often considered as a stress responsive transcription factor complex. Being at the receiving end of several signal transduction cascades, APl activity converts extracellular signals from, for example, growth factor receptors, through mitogen activated protein kinase (MAPK) into changes in gene expression via expression of AP1 responsive target genes. The activity of APl is regulated at different levels-transcriptional and post-transcriptional; it is also modulated by interactions with other transcriptional regulators. APl activity is implicated in a wide range of biological processes, including cell proliferation, differentiation, apoptosis, and oncogenesis. ${ }^{23}$ Here we will give a brief summary of the current knowledge and understanding of API functions in bone development and will focus on the role of APl in signal transduction in osteoclasts. These data were largely obtained from an analysis of genetically modified mice and cells, in which specific APl genes were ectopically expressed, constitutively or conditionally inactivated, mutated, or replaced by each other.

\section{AP1 PROTEINS IN BONE DEVELOPMENT}

APl proteins have important roles as key regulators of bone development. ${ }^{2}$ The generation of transgenic mice overexpressing Fos proteins has underlined the function of APl in osteoblasts, the bone forming cells, which are affected by the activity of different Fos proteins. Fos overexpression induces osteosarcomas, a bone tumour characterised by the transformation of cells of the osteoblastic lineage. ${ }^{4}$ On the other hand, mice overexpressing either a Fos target gene, Fral, which is also known as Fos-like antigen 1, Fosll, or the short isoform of FosB, $\Delta$ FosB, develop osteosclerosis, which is characterised by increased bone mass due to enhanced osteoblast differentiation. ${ }^{56}$ None of the APl members seem to be essential in determining the osteoblastic lineage. The function of APl in the development of the skeleton is not restricted to the mesenchymal lineage. Fos is also essential for osteoclast differentiation, as demonstrated by the complete absence of osteoclasts in mice lacking Fos (see below).

To better understand how Fos and Fral control osteoblast and osteoclast differentiation, conditional alleles of Fos and Fral were generated. The embryonic lethality caused by inactivation of Fral in the placenta was rescued with a conditional allele using MORE-cre mice, which results in specific deletion of Fral in the embryo proper. The mutant mice are viable but develop osteopenia, a mild form of osteoporosis due to decreased osteoblast differentiation (Eferl R and Wagner E, personal communication). The phenotype of Fral deficient osteoblasts correlates with the osteoblastic phenotype seen upon Fral overexpression. These data indicate that the expression level of Fos proteins can regulate the activity of the osteoblastic lineage. Interestingly, gene replacement of Fos by Fral showed functional equivalence of these two proteins.? Finally, inactivation of Fra2 gives rise to pups, which also exhibit severe osteoporosis and die at birth, probably due to heart failure (Eferl R and Wagner E, unpublished data).

Jun proteins are essential for mouse development, because absence of these proteins causes embryonic death. ${ }^{2}$ Conditional mutagenesis using the Cre-lox system provided important new insights into the functions of Jun and JunB in bone development. Chondrocyte-specific deletion of Jun leads to a failure of intravertebral disc formation, and mutant mice develop severe scoliosis. ${ }^{8}$ On the other hand, conditional deletion of JunB with the embryo-specific MORE-Cre line rescues the lethality, although the mutant mice develop severe osteoporosis characterised by defects in both osteoblasts and osteoclasts (Kenner L and Wagner E, unpublished data).

\section{SIGNALLING IN OSTEOCLASTS}

The signal transduction pathways operating in osteoclastogenesis have been extensively studied. We are beginning to understand how extracellular stimuli through intracellular signalling lead to the expression and activation of key transcription factors. ${ }^{9}$ Osteoclast differentiation is controlled by two essential cytokines, M-CSF and RANKL (fig 1 and for review see Karsenty and Wagner ${ }^{1}$ ). The key function of M-CSF was demonstrated by the analysis of a naturally occurring op/op mutation in mice, which carries an inactivating point mutation in the gene encoding $\mathrm{M}-\mathrm{CSF} .^{10} \mathrm{op} / \mathrm{op}$ mice are osteopetrotic owing to a lack of macrophage and osteoclast differentiation and thus of bone resorption. The defect can be rescued by injection of exogenous $\mathrm{M}-\mathrm{CSF}$, as well as by crossing the op/op mice with mice overexpressing the antiapoptotic protein Bcl2. These results show that M-CSF acts as a growth and survival factor for the common monocytic precursor shared between macrophages and osteoclasts.

Abbreviations: AP, activating protein; IFN, interferon; JNK, Jun $\mathrm{N}$-terminal kinase; MAPK, mitogen activated protein kinase; MAPKK, mitogen activated protein kinase kinase; M-CSF, macrophage colony-stimulating factor; RANKL, receptor activator of NF-KB ligand; TNF, tumour necrosis factor; TRAF, TNF receptor associated factor 


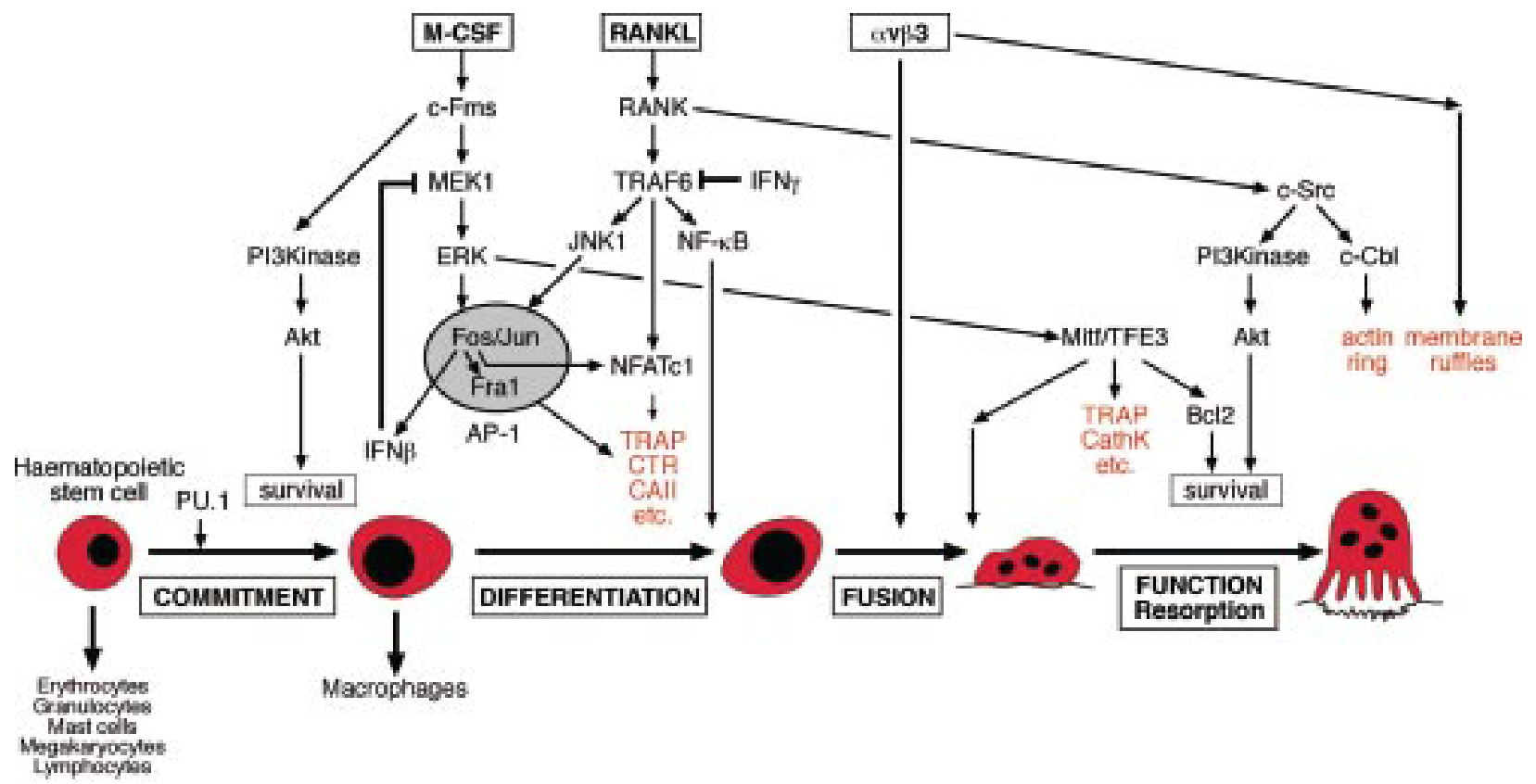

Figure 1 Signalling in osteoclast differentiation and function. M-CSF and RANKL are essential growth factors, which after binding to their receptors trigger a signalling cascade leading to the activation of key transcription factors such as Fos and Mitf, which in turn lead to the expression of osteoclast-specific target genes.

The second cytokine, RANKL, was first characterised as a ligand for the osteoclast inhibitory factor osteoprotegerin, a circulating decoy receptor belonging to the tumour necrosis factor $\alpha$ (TNF $\alpha)$ receptor family. ${ }^{11}{ }^{12}$ Gene inactivation studies demonstrated that RANKL, through binding to its receptor RANK, is essential for osteoclastogenesis, but does not affect macrophage differentiation. ${ }^{13}{ }^{14}$ Thus, RANKL is the key molecule controlling the switch between macrophages and osteoclasts. Gene inactivation experiments have also made it possible to identify the transcription factors specifically controlling the osteoclast switch. Mice lacking Fos and mice lacking two members of the NF- $\mathrm{KB}$ family, p50 and p52, display very similar phenotypes. ${ }^{15-17}$ They are both osteopetrotic owing to a block in osteoclast differentiation, while macrophages accumulate in the bone marrow .

The exact signalling pathway connecting RANKL to NF- $\mathrm{KB}$ is still unclear. The requirement of the TNF receptor associated factor 6 (TRAF6) for NF- $\mathrm{KB}$ activation is well established. Two different mouse lines lacking TRAF6 were generated, which both are osteopetrotic, but display significant differences. In one line, osteoclast differentiation is impaired, ${ }^{18}$ whereas in the second line osteoclasts do differentiate, but are inactive. ${ }^{19}$ In both lines, the interleukin $\mathrm{l}$ induced activation of NF- $\mathrm{\kappa B}$ is completely blocked. The role of TRAF6 in NF- $\mathrm{KB}$ activation was further confirmed by studying the mechanism by which type II interferon $\gamma$ (IFN $\gamma$ ) inhibits osteoclast differentiation. IFN $\gamma$ increased the ubiquitin mediated degradation of TRAF6, leading to a block in RANKL induced NF- $\kappa B .{ }^{20}$

\section{OSTEOCLASTS AND AP1 ACTIVITY}

The generation of multiple knockout mice affecting APl signalling pathways has permitted a more complete dissection of APl regulation in osteoclasts. RANKL is a known inducer of JNKs, which phosphorylate the Jun component of APl. IFN $\gamma$ was also shown to block RANKL induced JNK activation. Using JNK1 or JNK2 deficient monocytes, we have shown that inactivation of JNK1, but not of JNK2, leads to decreased osteoclast differentiation in vitro. Similar defects were seen when monocytes were isolated from mice expressing a phosphorylation deficient Jun (JunAA). Moreover, JNKl protects monocytes against RANKL induced apoptosis independently of Jun phosphorylation. ${ }^{21}$

The early embryonic lethality observed in mice lacking Jun or JunB long prevented the study of Jun functions in osteoclasts. Recently, monocytes lacking Jun or JunB were successfully generated using Cre mediated conditional deletion. A decrease in osteoclast differentiation was observed in vitro with both Jun or JunB deficient monocytes, while the absence of JunD had no effect. ${ }^{21}$ These data indicate that Jun and JunB are both probably partners of Fos in osteoclast differentiation.

Although the essential function of Fos for osteoclast differentiation has long been established, we are only just beginning to understand how Fos is regulated during osteoclast differentiation and, more importantly, what the key downstream targets are (see below). Type I interferon (IFN $\beta$ ) inhibits osteoclast differentiation by post-transcriptionally blocking Fos expression. ${ }^{22}$ Surprisingly, Fos itself directly regulates IFN $\beta$ synthesis in osteoclasts, thereby establishing an autoinhibitory loop (fig 1). Moreover, post-transcriptional modifications of Fos in response to M-CSF stimulation were identified. Fos was shown to be phosphorylated in its C-terminal domain on serine 362 and 374 by ERK (also known as MAPK1), and the ERK dependent kinase RSK-2. Phosphorylation of these two sites is believed to stabilise Fos. Pretreatment of osteoclast progenitors with IFN $\beta$ inhibits M-CSF induced ERK activation. Finally, the inhibition of the upstream ERK-activating kinase MEKl (also known as mitogen activated protein kinase kinase 1, MAPKK1) was proposed as the mechanism by which IFN $\beta$ blocks osteoclast differentiation (David J-P and Wagner E, unpublished data).

In addition to IFN $\beta$, the Fos related protein Fral has been described as a Fos target in osteoclasts. ${ }^{23}$ Although Fral is not essential for osteoclast differentiation, decreased osteoclast differentiation was seen in mice lacking Fral, confirming that Fral can potentiate the efficiency of osteoclastogenesis. ${ }^{23}$ 


\section{RANKL DEPENDENT GENE EXPRESSION}

To explore comprehensively the signalling pathways downstream of RANKL, a genome-wide screening of RANKL inducible genes was performed.$^{24}$ Microarray analyses of wildtype precursors treated with RANKL showed that the expression of several transcription factors, in particular of NFATcl, is strongly up regulated by RANKL. NFATcl, encoding a transcription factor that interacts with APl, was identified as a TRAF6 and Fos target gene in osteoclasts. Northern blot analysis showed that NFATcl expression is abolished in Fos-/precursors. ${ }^{24}$ A key function of NFATcl in osteoclastogenesis was further demonstrated by showing that no osteoclasts could be generated from embryonic stem cells lacking NFATcl. In addition, ectopic expression of NFATcl in osteoclast progenitors induced osteoclast differentiation in the absence of RANKL. These data suggest that NFATcl is a key downstream target and partner of c-Fos essential for osteoclast differentiation.

\section{Fos DEPENDENT GENE EXPRESSION}

Genome-wide analyses of Fos target genes using both cDNA and oligonucleotide based microarrays was also performed to discover new downstream effectors of Fos signalling. A comparison between wild-type and Fos-/- precursors in osteoclastogenic cultures disclosed preferential expression of a number of interferon inducible genes in wild-type cultures (our unpublished results). This led to the identification of the IFN $\beta$ mediated negative feedback regulation of osteoclastogenesis. ${ }^{22}$ This analysis again showed the lack of NFATcl expression in Fos-/- precursors. Importantly, the introduction of an activated form of NFATc into Fos-/precursor cells rescued osteoclast formation as well as bone resorption and restored transcription of osteoclast marker genes (Matsuo et al, manuscript in preparation), indicating that the lack of transcriptional activation of NFATcl is the cause of the differentiation block in the osteoclast precursors lacking Fos. It appears that NFATcl acting as a direct target gene of Fos and RANKL signalling is a new key regulator for terminal differentiation of osteoclasts.

\section{ACKNOWLEDGEMENTS}

The IMP is supported by Boehringer-Ingelheim and EFW thanks PD for help in preparing the manuscript.

\section{Authors' affiliations}

E F Wagner, IMP, Research Institute of Molecular Pathology, Dr. Bohr-Gasse 7, A-1030 Vienna, Austria

K Matsuo, Keio University School of Medicine, Tokyo, Japan

Correspondence to: Dr E F Wagner; wagner@imp.univie.ac.at

\section{REFERENCES}

1 Karsenty G, Wagner EF. Reaching a genetic and molecular understanding of skeletal development. Dev Cell 2002;2:389-406.
2 Jochum W, Passegue E, Wagner EF. AP-1 in mouse development and tumorigenesis. Oncogene $2001 ; 20: 2401-12$.

3 Shaulian E, Karin M. AP-1 as a regulator of cell life and death. Nat Cell Biol. 2002;4:E131-6.

4 Grigoriadis $\mathbf{A E}$, Schellander K, Z Wang Q, Wagner EF. Osteoblasts are target cells for transformation in c-fos transgenic mice. J Cell Biol 1993; 122:685-701.

5 Jochum W, David JP, Elliott C, Wutz A, Plenk HJ, Matsuo K, et al. Increased bone formation and osteosclerosis in mice overexpressing the transcription factor Fra-1. Nat Med 2000;6:980-4; rratum in: Nat Med 2000;6:1412.

6 Sabatakos G, Sims NA, Chen J, Aoki K, Kelz MB, Amling M, et al. Overexpression of delta FosB transcription factor(s) increases bone formation and inhibits adipogenesis. Nat Med 2000;6:985-90.

7 Fleischmann A, Hafezi F, Elliott C, Reme CE, Ruther U, Wagner EF. Fra-1 replaces c-Fos-dependent functions in mice. Genes Dev 2000; 14:2695-700.

8 Behrens A, Haigh J, Mechta-Grigoriou F, Nagy A, Yaniv M, Wagner $\mathrm{EF}$. Impaired intervertebral disc formation in the absence of Jun. Development 2003;130:103-9.

9 Wagner EF, Karsenty G Genetic control of skeletal development. Curr Opin Genet Dev 2001; 1 1:527-32

10 Yoshida H, Hayashi S, Kunisada T, Ogawa M, Nishikawa S, Okamura $\mathrm{H}$, et al. The murine mutation osteopetrosis is in the coding region of the macrophage colony stimulating factor gene. Nature 1990;16:391-6.

11 Lacey DL, Timms E, Tan HL, Kelley M, Dunstan CR, Burgess T, et al. Osteoprotegerin ligand is a cytokine that regulates osteoclast differentiation and activation. Cell 1998;93:165-76.

12 Yasuda H, Shima N, Nakagawa N, Mochizuki SI, Yano K, Fujise N, et al. Identity of osteoclastogenesis inhibitory factor (OCIF) and osteoprotegerin (OPG): a mechanism by which OPG/OCIF inhibits osteoclastogenesis in vitro. Endocrinology 1998;139:442-4.

13 Dougall WC, MGlaccum M, Charrier K, Rohrbach K, Brasel K, De Smedt $\mathrm{T}$, et al. RANK is essential for osteoclast and lymph ode development. Genes Dev 1999; 13:2412-24.

14 Kong YY, Boyle WJ, Penninger JM. Osteoprotegerin ligand: a common link between osteoclastogenesis, lymph node formation and lymphocyte development. Immunol Cell Biol 1999;77:188-93.

15 Grigoriadis AE, Wang ZQ, Cecchini MG, Hofstetter W, Felix R, Fleisch $\mathrm{HA}$, et al. c-Fos: a key regulator of osteoclast-macrophage lineage determination and bone remodeling. Science 1994;266:443-8.

16 Franzoso G, Carlson L, Xing L, Poljak L, Shores EW, K Brown D, et al. Requirement for NF-kappaB in osteoclast and B-cell development. Genes Dev 1997: 1 1:3482-96.

17 lotsova V, Caamano J, Loy J, Yang Y, Lewin A, Bravo R. Osteopetrosis in mice lacking NF-kappaB 1 and NF-kappaB2. Nat Med 1997;3:1285-9.

18 Naito A, Azuma S, Tanaka S, Miyazaki T, Takaki S, Takatsu K, et al. Severe osteopetrosis, defective interleukin-1 signalling and lymph node organogenesis in TRAF6-deficient mice. Genes Cells 1999;4:353-62.

19 Lomaga MA, Yeh WC, Sarosi I, Duncan GS, Furlonger C, Ho A, et al. TRAF6 deficiency results in osteopetrosis and defective interleukin-1, CD40, and LPS signaling. Genes Dev 1999;13:1015-24.

20 Takayanagi H, Ogasawara K, Hida S, Chiba T, Murata S, Sato K, et al. T-cell-mediated regulation of osteoclastogenesis by signalling crosstalk between RANKL and IFN-gamma. Nature 2000;408:600-5.

21 David JP, Sabapathy K, Hoffmann O, Idarraga MH, E Wagner F JNK 1 modulates osteoclastogenesis through both c-Jun

phosphorylation-dependent and -independent mechanisms. J Cell Sci 2002; $115(\mathrm{Pt} 22): 4317-25$.

22 Takayanagi H, Kim S, Matsuo K, Suzuki H, Suzuki T, Sato K, et al. RANKL maintains bone homeostasis through c-Fos-dependent induction of interferon-beta. Nature 2002;416:744-9.

23 Matsuo K, J Owens M, Tonko M, C Elliott, T Chambers J, Wagner EF. Fosl 1 is a transcriptional target of c-Fos during osteoclast differentiation. Nat Genet 2000;24:184-7.

24 Takayanagi $\mathbf{H}$, Kim S, Koga $T$, Nishina $H$, Isshiki $M, H$ Yoshida, et al. Induction and activation of the transcription factor NFATc l (NFAT2) integrate RANKL signaling in terminal differentiation of osteoclasts. Dev Cell 2002;3:889-901. 